\title{
Regulation of Male Fertility by Bone
}

\author{
G. KARSENTY \\ Columbia University, Department of Genetics and Development, New York, New York 10032 \\ Correspondence: gk2172@columbia.edu
}

\begin{abstract}
A broadly held view of bone is that it is a tissue defined by its mechanical and scaffolding properties, whose interaction with other organs of the body is similar to that exerted by an armor protecting them. In the last 10 years, using mouse genetics, this view of bone as an assembly of inert calcified tubes has considerably evolved to a much more dynamic picture. It is now clear that the skeleton is not a simple target tissue for the hormones secreted by other organs, but it is an endocrine organ itself. Genetics and biochemical evidence have established that osteocalcin, an osteoblast-derived hormone, is an endocrine regulator of energy metabolism and male fertility. These novel hormonal connections between bone, energy metabolism, and reproduction underscore the concept of functional dependence in physiology and the importance of genetic approaches to identify novel endocrine regulations.
\end{abstract}

The last 20 years have been a period of tremendous progress in molecular physiology and in what is now called systems biology. At the same time that developmental biology was revolutionized through the use of mouse genetics to study the function of a single gene in vivo, there have been, through the same means, spectacular advances in our knowledge of the genetic and molecular control of physiological functions in vertebrates. Among these many conceptual and experimental advances one can cite the, ever growing in complexity, elucidation of the control of appetite (Friedman and Halaas 1998; Spiegelman and Flier 2001); the identification of a molecular clock (Albrecht et al. 1997), and of its components and of their respective functions; the identification of genes controlling longevity such as Sir1 and Insulin (Bell et al. 1979; Pillus and Rine 1989); and the realization that nuclear receptors regulate in a major way heart function, energy metabolism, and skin integrity (Kliewer et al. 1992; Huss et al. 2002; Schreiber et al. 2003; Li et al. 2005). In the field of skeleton biology this mouse genetics-based approach has been very fertile, probably because skeleton is a late acquisition during evolution and, therefore, it is more likely that gene functions are conserved between mice and humans (Karsenty and Wagner 2002). Among the many conceptual and biological advances elicited in the field of the skeletal physiology by the use of mouse genetics, one can cite the identification of all the components of the RankL-dependent pathway and the demonstration of their function in the control of osteoclast biology (Lacey et al. 1998; Kong et al. 1999); the identification of thyroid-stimulating hormone and follicle-stimulating hormone (Abe et al. 2003; Sun et al. 2006), two pituitary hormones, as regulators of bone mass; and the realization that bone formation and bone resorption are regulated by the sympathetic nervous system (Takeda et al. 2002; Elefteriou et al. 2005). All these discoveries made possible through mouse genetics have contributed to establishing that previously unsuspected biological links exist between various organs: that is, between fat and bone, between pituitary gland and bone, and between hypothalamus and bone. As a result it becomes increasingly evident that, if we want to make even more progress, skeletal physiology has to be studied in an integrative manner in an intact animal.

The discovery of the above-cited examples, as well as of many other new physiologies, raises the question of how these regulatory loops take place at the molecular level. The answer to this question is more or less advanced depending on which physiological process one looks at. To help address this question, in an increasing number of cases the completion of the sequencing of the human genome provides new opportunities to identify proteins of interest, to gather data suggesting a molecular cascade, and, eventually, to test these hypotheses in vivo. Indeed the ability that is now more widespread than before to inactivate genes of interest by either classical homologous recombination in embryonic stem (ES) cells or by RNA interference allows relatively quick verification of the validity of a given hypothesis. This is particularly important, as gene inactivating itself has become less labor-intensive and more affordable to most scientists. For all these reasons, and also because of the impact it will have on the understanding and treatment of many human degenerative diseases, it is likely that molecular physiology and system biology through the use, at least in part, of functional genomics are both going to gain further preeminence in the years to come.

\section{GENETIC BASIS FOR THE COMMON ENDOCRINE CONTROL OF BONE AND ENERGY METABOLISMS}

In the last 15 years my laboratory has become increasingly engaged in an intensive and systematic effort to define, and to understand molecularly, the role of bone 


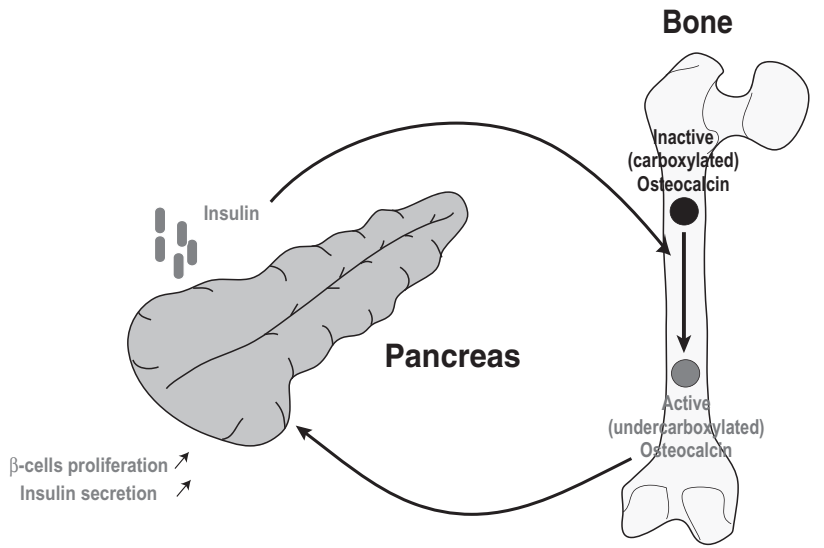

Figure 1. Bone regulates energy metabolism. Osteocalcin is an osteoblast-specific secreted molecule that, when undercarboxylated, acts as a hormone favoring $\beta$-cell proliferation, insulin secretion, and sensitivity. The mechanism activating osteocalcin is regulated in osteoblasts by insulin signaling, which favors osteocalcin bioavailability by promoting its decarboxylation. as an endocrine regulator of energy metabolism, reproduction and now of other functions (Karsenty 2006). This investigation was initiated because of a spectrum of clinical observations linking bone modeling and remodeling to the control of energy metabolism and fertility. That gonadal failure favors the appearance of osteoporosis whereas obesity seems to protect from osteoporosis and its deleterious consequences was an argument to propose the following working hypothesis: Bone mass, energy metabolism or at least some aspects of it, and reproduction may be regulated by the same hormones. As will be presented later, this hypothesis was not only based on an interpretation of the clinical literature but also tested experimentally through genetic and molecular tools previously described, generating specific mutant mouse strains.

In our first attempt to test this hypothesis we asked whether a hormone, such as leptin, made by adipocytes and regulating appetite, energy expenditure, and reproduction, did influence bone mass. Over the course of 10 years we have shown that (1) leptin is a very powerful inhibitor of bone mass accrual in both mice and humans that acts by reducing bone formation and increasing bone resorption; (2) this action occurs exclusively through a neuronal relay; (3) this relay occurs via hypothalamic neurons; (4) the sympathetic tone and CART are two mediators linking hypothalamic neurons to osteoblasts; and (5) these two pathways, the sympathetic tone and CART, act in osteoblasts to affect bone formation and resorption (Ducy et al. 2000; Takeda et al. 2002; Elefteriou et al. 2005; Fu et al. 2005; Shi et al. 2008).

Following the logic of most endocrine regulations, which always include a feedback loop, and based on the fact that activity of bone cells is controlled by so many hormones, we can hypothesize that bone cells must in turn regulate some aspects of energy metabolism. In full support of this hypothesis we have shown that an osteoblast-specific secreted molecule, osteocalcin, in its undercarboxylated form, acts as a hormone to regulate energy metabolism through several synergistic functions: favoring pancreatic $\beta$-cell proliferation, increasing insulin expression and secretion, enhancing insulin sensitivity, and promoting energy expenditure (Lee et al. 2007;
Ferron et al. 2010; Fulzele et al. 2010; Fig. 1). Remarkably, the metabolic activity of osteocalcin is modulated, indirectly, by leptin and possibly more extracellular cues (Hinoi et al. 2008; Yoshizawa et al. 2009). Hence, this body of work has verified the first aspect of our working hypothesis, namely that there is a reciprocal regulation of bone remodeling and energy metabolism. These results provided the first evidence that the skeleton is an endocrine organ favoring whole-body glucose homeostasis and energy expenditure.

\section{OSTEOCALCIN, A MOLECULE LINKING BONE MASS, ENERGY METABOLISM, AND REPRODUCTION}

The discovery of hormonal functions of osteocalcin raised multiple questions with great biological and medical importance. Chief among them is to elucidate the signaling events triggered by this hormone in target cells. A prerequisite to address this question was the identification of a specific receptor for osteocalcin. A second question, with even broader implications, was to determine whether osteocalcin, like many hormones, has functions in addition to those exerted on energy metabolism. The wellknown regulation of bone remodeling by gonads provides an ideal setting to address the aforementioned question. In light of this hypothesis, the proposal that bone influences fertility became of great conceptual importance.

That menopause favors bone loss is a well established fact (Riggs et al. 1998; Khosla et al. 2001; Manolagas et al. 2002; Nakamura et al. 2007; Khosla 2010). What this medical observation means biologically is that gonads, mostly through sex steroid hormones, affect in one way or another the functions of bone cells, an aspect of bone physiology that will not be discussed here. What the regulation of bone mass accrual by gonads suggests is that bone in turn, in its endocrine capacity, may affect the reproductive functions in one or both genders. Verifying this hypothesis is of course of great conceptual importance as it would further enhance the emerging importance of bone as an endocrine organ.

Testing this hypothesis in vivo was admittedly greatly helped by a striking feature of mutant mice lacking 
osteocalcin. Indeed, although female Osteocalcindeficient mice were normally fertile, the male mutant mice were rather poor breeders, whether their partners were wild type (WT) or Osteocalcin-deficient. As was the case for energy metabolism, the demonstration that this phenotype betrays a true biological function of osteocalcin was made more complete and convincing because of the availability of gain $\left(E s p^{-/-}\right)$and loss-of-function (Osteocalcin ${ }^{-/-}$) mutations for Osteocalcin (Lee et al. 2007). Osteocalcin-deficient mice showed a decrease in testes, epidydimes, and seminal vesicle weights, whereas the weight of these organs was increased in Esp-deficient mice. The spermogram of male Osteocalcin-deficient mice showed a $50 \%$ decrease in sperm count, whereas that of male Esp-deficient mice showed a 30\% increase in this parameter, and Leydig cell maturation appeared to be halted in absence of Osteocalcin (Oury et al. 2011). These features suggested that osteocalcin might favor testosterone synthesis. Again, this was verified by a simple but always powerful co-culture assay, and then in vivo (Oury et al. 2011).

The supernatants of WT osteoblasts in culture increased testosterone production by Leydig cells of the testes, a feat no other mesenchymal cells could achieve to the same extent. In this assay osteoblast culture supernatants did not affect estrogen production by ovarian explants. In contrast, the supernatant of Osteocalcindeficient osteoblasts cultures did not affect hormone production by Leydig cells. Again, further cell-based and in vivo assays showed that osteocalcin favors the expression of all the genes necessary for testosterone biosynthesis in Leydig cells (Oury et al. 2011). Accordingly, circulating testosterone levels are low in Osteocalcin ${ }^{-1-}$ and high in $E s p^{-/-}$mice. In contrast, osteocalcin does not affect expression of the genes coding for the conversion of testosterone in estrogen and estrogen levels are within the normal range in $\mathrm{Esp}^{-/-}$and Osteocalcin ${ }^{-/-}$mice (Oury et al. 2011). That Osteocalcin ${ }^{-/-}$mice develop a peripheral testicular insufficiency in the face of high levels of pituitary hormones (luteinizing hormone and follicle-stimulating hormone) underscores the importance of the regulation of male reproduction by osteocalcin and suggests that some patients with peripheral testicular insufficiency may have a defect in the bone-testis axis.

To formally establish that osteocalcin is regulating testosterone production as a bone-derived hormone, and not as a testis-secreted growth factor, mice lacking Osteocalcin only in osteoblasts were generated. Male Osteocalcin osb $^{-}$mice had the same testosterone production defect as the classical Osteocalcin ${ }^{-/-}$mice, whereas deletion of Osteocalcin in Leydig cells did not affect male fertility (Oury et al. 2011). Taken together, these experiments established that osteocalcin is a bone-derived hormone favoring fertility in male mice by promoting Leydig cell maturation and testosterone production (Fig. 2). In other words they verified that, for at least one gender, there is an endocrine regulator of reproduction by the skeleton. They also revealed a novel notion in endocrinology of reproduction, that there

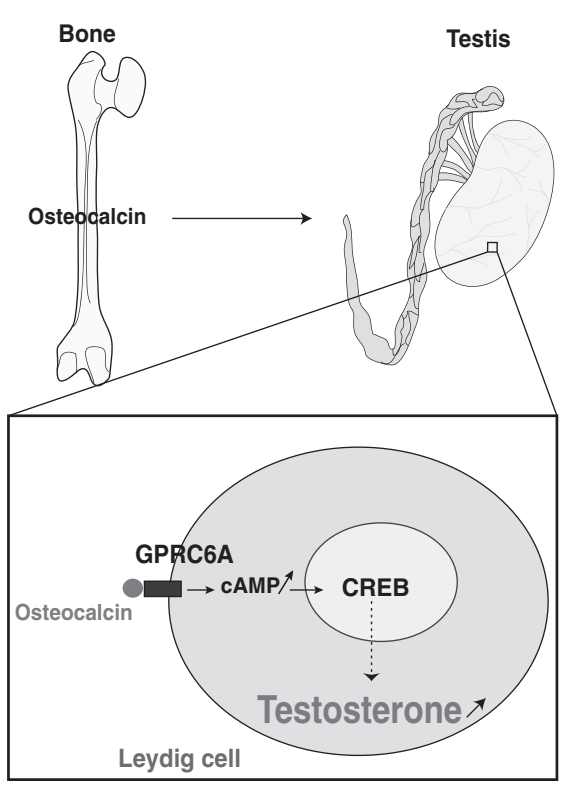

Figure 2. Bone regulates male fertility. Osteocalcin secreted by bone favors, in a cAMP response element binding (CREB) protein-dependent manner, testosterone production by the testes. This novel osteocalcin endocrine function is mediated through its binding to GPRC6A, a G-coupled receptor expressed in Leydig cells.

are major differences between males and females in the regulation of this function.

With hindsight these observations were both surprising and expected. They were surprising because bone is not classically seen as an endocrine organ, much less one regulating reproduction. They were surprising also because of the absence of regulation of fertility in females. On the other hand, they were expected because the feedback rule that applies to most endocrine regulations suggested, given the fact that sex steroid hormones regulate bone mass in both genders, that such a regulation may exist. In broader terms, the existence of this function increases the importance of osteocalcin as a hormone.

In the molecular era the identification of a novel hormone immediately begs the question of its mechanism of action. A prerequisite to answering this question is to characterize a receptor to which this hormone would bind specifically on its target cells. In the case of osteocalcin this was achieved through a two-step strategy taking advantage of the fact that osteocalcin regulates fertility in males but not in females (Oury et al. 2011).

In the first step it was asked what is the signal transduction pathway affected by osteocalcin in two target cells, the $\beta$-cell of the pancreas and the Leydig cell of the testis (Lee et al. 2007; Oury et al. 2011; Pi et al. 2011). This approach identified the production of cAMP as the only intracellular signaling event reproducibly triggered by osteocalcin in these two cell types. We interpreted this result as suggesting that the osteocalcin receptor is probably a G protein coupled receptor (GPCR) linked to the adenylate cyclase. Therefore, in the second step of this experimental strategy, taking advantage of the dichotomy 
of function of osteocalcin between males and females, we asked whether there were orphan GPCRs expressed at a higher level (fivefold higher) in testes than in ovaries. Out of more than 100 orphan GPCRs submitted to this test, 22 were more expressed in testes than in ovaries and only four were expressed predominantly or only in Leydig cells (Oury et al. 2011). One of these four orphan GPCRs, GPRC6A, was a particularly good candidate to be an osteocalcin receptor, because its inactivation in mice results in metabolic and reproduction phenotypes similar to those seen in Osteocalcin ${ }^{-/}$mice (Pi et al. 2008). Furthermore, and although it was never tested through any binding assays, it had been proposed that GPRC6A was a calcium-serving receptor working better in the presence of osteocalcin (Oury et al. 2011).

Although, the aforementioned result could not be reproduced, several criteria formally identified GPRC6A as an osteocalcin receptor present in Leydig cells (Pi et al. 2008; Oury et al. 2011; Fig. 2). First, there is direct binding of osteocalcin to WT but not to GPRC6A-deficient Leydig cells; second, osteocalcin increased cAMP production in WT but not in GPRC6A-deficient Leydig cells; third, and more to the point, a Leydig cell-specific deletion of GPRC6A revealed a reproduction phenotype caused by low testosterone production similar, if not identical, to that seen in the case of osteocalcin inactivation; fourth, in an even more convincing experiment compound heterozygous mice lacking one copy of Osteocalcin and one copy of GPRC6A had a reproduction phenotype identical in all aspects to that seen in Osteocalcin $^{-1-}$ or GPRC $6 A^{-/-}$mice. The identification of GPRC6A as osteocalcin receptor led subsequently to the realization that cAMP response element binding protein is a transcriptional effector of osteocalcin regulation of testosterone biosynthesis, by favoring the expression of key enzymes of this biosynthetic pathway in Leydig cells (Oury et al. 2011; Fig. 2). The identification of GPRC6A now allows us to address many more questions, chief among them being to identify other functions of osteocalcin. It allows us also to perform a more sophisticated dissection of the osteocalcin molecular mode of action in known, and yet to be identified, target cells.

Last, the function of osteocalcin as a regulator of testosterone production has been extended to men. The group of Dr Khosla showed recently that there is a significant association between serum osteocalcin and testosterone levels during midpuberty in males, but not in females (Kirmani et al. 2011). They postulate that this axis may be most relevant during rapid skeletal growth in adolescent human males to help maximize bone size.

\section{CONCLUSION}

This work demonstrates how powerful the concept of functional dependence in physiology is, and how intimately connected are all the organs; genetic dissection in model organisms provides an ideal tool to link multiple physiologies and therefore multiple medical disciplines. As of today and for the foreseeable future, mouse genetics is the most powerful tool to map out and study all the interorgan connections that exists in vertebrates.

If we now narrow our analysis to the skeleton physiology itself, this whole-organism molecular genetic approach has shown that (1) the appearance of the bony skeleton may explain in a simple way the appearance of a hormone like leptin with bony vertebrates during evolution; (2) the functions of the skeleton are not all known yet, but the ones that are indicate that skeleton physiology affects many more organs and functions than the skeleton itself, as it already affects glucose homeostasis, energy expenditure, and fertility; and, this is a major outcome of this work, (3) if the skeleton affects so significantly two major functions and possibly others, then it is likely that vertebrate physiology is best studied in animal models containing a bony skeleton. Another question raised by this work is that, if the osteoblast is such an important endocrine cell, then we need to understand molecularly why bone mass decreases steadily over time.

If we look in an even more focused way, not at the skeleton in general, but at osteocalcin in particular, we ought to be struck by the fact that this hormone affects functions that go awry during aging. This is important because traditionally the skeleton is viewed as a victim of the aging process and it is true that osteoporosis is a manifestation of aging. However, the two functions already described by osteocalcin identify it as a fitness hormone, affecting processes that deteriorate or disappear with aging. These findings therefore suggest the testable hypothesis that bones may be a determinant as much as a victim of the aging process. This is not meant to say that bone would be the main endocrine determinant of aging; it is simply meant to suggest that we may not have exhausted the knowledge about whole-organism physiology that can be gained from the study of this particular organ.

\section{REFERENCES}

Abe E, Marians RC, Yu W, Wu XB, Ando T, Li Y, Iqbal J, Eldeiry L, Rajendren G, Blair HC, et al. 2003. TSH is a negative regulator of skeletal remodeling. Cell 115: 151-162.

Albrecht U, Sun ZS, Eichele G, Lee CC. 1997. A differential response of two putative mammalian circadian regulators, mper 1 and mper2, to light. Cell 91: 1055-1064.

Bell GI, Swain WF, Pictet R, Cordell B, Goodman HM, Rutter WJ. 1979. Nucleotide sequence of a cDNA clone encoding human preproinsulin. Nature 282: 525-527.

Ducy P, Amling M, Takeda S, Priemel M, Schilling AF, Beil FT, Shen J, Vinson C, Rueger JM, Karsenty G. 2000. Leptin inhibits bone formation through a hypothalamic relay: A central control of bone mass. Cell 100: 197-207.

Elefteriou F, Ahn JD, Takeda S, Starbuck M, Yang X, Liu X, Kondo H, Richards WG, Bannon TW, Noda M, et al. 2005. Leptin regulation of bone resorption by the sympathetic nervous system and CART. Nature 434: 514-520.

Ferron M, Wei J, Yoshizawa T, Del Fattore A, DePinho RA, Teti A, Ducy P, Karsenty G. 2010. Insulin signaling in osteoblasts integrates bone remodeling and energy metabolism. Cell 142: 296-308.

Friedman JM, Halaas JL. 1998. Leptin and the regulation of body weight in mammals. Nature 395: 763-770.

Fu L, Patel MS, Bradley A, Wagner EF, Karsenty G. 2005. The molecular clock mediates leptin-regulated bone formation. Cell 122: 803-815. 
Fulzele K, Riddle RC, DiGirolamo DJ, Cao X, Wan C, Chen D, Faugere MC, Aja S, Hussain MA, Bruning JC, et al. 2010. Insulin receptor signaling in osteoblasts regulates postnatal bone acquisition and body composition. Cell 142: 309-319.

Hinoi E, Gao N, Jung DY, Yadav V, Yoshizawa T, Myers MG Jr, Chua SC Jr, Kim JK, Kaestner KH, Karsenty G. 2008. The sympathetic tone mediates leptin's inhibition of insulin secretion by modulating osteocalcin bioactivity. J Cell Biol 183: $1235-1242$.

Huss JM, Kopp RP, Kelly DP. 2002. Peroxisome proliferatoractivated receptor coactivator- $1 \alpha \quad$ (PGC- $1 \alpha)$ coactivates the cardiac-enriched nuclear receptors estrogen-related receptor- $\alpha$ and $-\gamma$. Identification of novel leucine-rich interaction motif within PGC-1 $\alpha$. J Biol Chem 277: 40265-40274.

Karsenty G. 2006. Convergence between bone and energy homeostases: Leptin regulation of bone mass. Cell Metab 4: 341-348.

Karsenty G, Wagner EF. 2002. Reaching a genetic and molecular understanding of skeletal development. Dev Cell 2: 389-406.

Khosla S. 2010. Update on estrogens and the skeleton. J Clin Endocrinol Metab 95: 3569-3577.

Khosla S, Melton LJ 3rd, Atkinson EJ, O'Fallon WM. 2001. Relationship of serum sex steroid levels to longitudinal changes in bone density in young versus elderly men. $J$ Clin Endocrinol Metab 86: 3555-3561.

Kirmani S, Atkinson EJ, Melton LJ 3rd, Riggs BL, Amin S, Khosla S. 2011. Relationship of testosterone and osteocalcin levels during growth. $J$ Bone Miner Res (in press).

Kliewer SA, Umesono K, Noonan DJ, Heyman RA, Evans RM. 1992. Convergence of 9-cis retinoic acid and peroxisome proliferator signalling pathways through heterodimer formation of their receptors. Nature 358: 771-774.

Kong YY, Boyle WJ, Penninger JM. 1999. Osteoprotegerin ligand: A common link between osteoclastogenesis, lymph node formation and lymphocyte development. Immunol Cell Biol 77: 188-193.

Lacey DL, Timms E, Tan HL, Kelley MJ, Dunstan CR, Burgess T, Elliott R, Colombero A, Elliott G, Scully S, et al. 1998. Osteoprotegerin ligand is a cytokine that regulates osteoclast differentiation and activation. Cell 93: 165-176.

Lee NK, Sowa H, Hinoi E, Ferron M, Ahn JD, Confavreux C, Dacquin R, Mee PJ, McKee MD, Jung DY, et al. 2007. Endocrine regulation of energy metabolism by the skeleton. Cell 130: $456-469$.

Li M, Messaddeq N, Teletin M, Pasquali JL, Metzger D, Chambon P. 2005. Retinoid X receptor ablation in adult mouse keratinocytes generates an atopic dermatitis triggered by thymic stromal lymphopoietin. Proc Natl Acad Sci 102: $14795-14800$.

Manolagas SC, Kousteni S, Jilka RL. 2002. Sex steroids and bone. Recent Prog Horm Res 57: 385-409.

Nakamura T, Imai Y, Matsumoto T, Sato S, Takeuchi K, Igarashi K, Harada Y, Azuma Y, Krust A, Yamamoto Y, et al. 2007. Estrogen prevents bone loss via estrogen receptor alpha and induction of Fas ligand in osteoclasts. Cell 130: 811-823.

Oury F, Sumara G, Sumara O, Ferron M, Chang H, Smith CE, Hermo L, Suarez S, Roth BL, Ducy P, et al. 2011. Endocrine regulation of male fertility by the skeleton. Cell 144: 796-809.

Pi M, Chen L, Huang MZ, Zhu W, Ringhofer B, Luo J, Christenson L, Li B, Zhang J, Jackson PD, et al. 2008. GPRC6A null mice exhibit osteopenia, feminization and metabolic syndrome. PLoS One 3: e3858.

Pi M, Wu Y, Quarles LD. 2011. GPRC6A mediates responses to osteocalcin in $\beta$-cells in vitro and pancreas in vivo. $J$ Bone Miner Res 26: 1680-1683.

Pillus L, Rine J. 1989. Epigenetic inheritance of transcriptional states in S. cerevisiae. Cell 59: 637-647.

Riggs BL, O'Fallon WM, Muhs J, O'Connor MK, Kumar R, Melton LJ 3rd. 1998. Long-term effects of calcium supplementation on serum parathyroid hormone level, bone turnover, and bone loss in elderly women. $J$ Bone Miner Res 13: $168-174$.

Schreiber SN, Knutti D, Brogli K, Uhlmann T, Kralli A. 2003. The transcriptional coactivator PGC-1 regulates the expression and activity of the orphan nuclear receptor estrogenrelated receptor $\alpha(E R R \alpha)$. J Biol Chem 278: 9013-9018.

Shi Y, Yadav VK, Suda N, Liu XS, Guo XE, Myers MG Jr, Karsenty G. 2008. Dissociation of the neuronal regulation of bone mass and energy metabolism by leptin in vivo. Proc Natl Acad Sci 105: 20529-20533.

Spiegelman BM, Flier JS. 2001. Obesity and the regulation of energy balance. Cell 104: 531-543.

Sun L, Peng Y, Sharrow AC, Iqbal J, Zhang Z, Papachristou DJ, Zaidi S, Zhu LL, Yaroslavskiy BB, Zhou H, et al. 2006. FSH directly regulates bone mass. Cell 125: 247-260.

Takeda S, Elefteriou F, Levasseur R, Liu X, Zhao L, Parker KL, Armstrong D, Ducy P, Karsenty G. 2002. Leptin regulates bone formation via the sympathetic nervous system. Cell 111: $305-317$.

Yoshizawa T, Hinoi E, Jung DY, Kajimura D, Ferron M, Seo J, Graff JM, Kim JK, Karsenty G. 2009. The transcription factor ATF4 regulates glucose metabolism in mice through its expression in osteoblasts. J Clin Invest 119: 2807-2817. 


\title{
$\$_{\text {CSH }}^{\infty}$ Cold Spring Harbor Symposia SYMPOSIA On Quantitative Biology
}

\section{Regulation of Male Fertility by Bone}

\author{
G. Karsenty
}

Cold Spring Harb Symp Quant Biol 2011 76: 279-283 originally published online August 22, 2011 Access the most recent version at doi:10.1101/sqb.2011.76.010934

References This article cites 33 articles, 5 of which can be accessed free at: http://symposium.cshlp.org/content/76/279.full.html\#ref-list-1

\section{License}

Email Alerting Receive free email alerts when new articles cite this article - sign up in Service the box at the top right corner of the article or click here. 